\title{
IDENTIFIKASI BAHAYA BEKERJA PADA DEPARTEMEN CASTING DENGAN HAZARD IDENTIFICATION RISK ASSESSMENT AND RISK CONTROL DI PT. PRIMA ALLOY STEEL
}

\author{
Gatot Basuki HM \\ Jurusan Teknik Perkapalan, Institut Teknologi Adhi Tama Surabaya \\ Email: gatotbasukihm@itats.ac.id
}

\begin{abstract}
ABSTRAK
PT. Prima Alloy Steel Universal merupakan perusahaan industri manufaktur yang memproduksi Velg kendaraan roda empat. Salah satu tahapan proses produksinya yaitu proses casting, Adanya risiko bagi pekerja akan terjadinya kecelakaan kerja sangat tinggi. Tujuan penelitian ini adalah melakukan identifikasi terhadap risiko bekerja di departemen casting dengan pendekatan Job Safety Analysis. sedangkan penilaian risiko serta penanggulangan risiko bahaya bekerja menggunakan metode HIRARC, hasil dari analisis tersebut digunakan untuk melakukan mitigasi terhadap setiap risiko yang terjadi di departemen casting. Hasil penelitian menunjukan bahwa Terdapat 5 aktivitas kerja dan 13 subaktivitas kerja di departemen casting yang mempunyai potensi bahaya bekerja. sedangkan penilaian risiko diperoleh 2 aktivitas kerja dengan potensi bahaya kategori extreme risk, 4 aktivitas kerja kategori high risk, 3 aktivitas kerja kategori moderate risk, 4 aktivitas kerja kategori low risk. Tindakan penanggulangan risiko dilakukan melalui perbaikan standart prosedur kerja (SOP) pada setiap subaktivitas. Subtitusi pada subaktivitas menggunakan alat berat seperti forklif saat mengganti matras motif dan design velg. Rekayasa engineering untuk mempermudah subaktivitas agar miminimalisir terjadinya kecelakaan kerja. Pengendalian administratif terkait penerapan instruksi kerja, memantau pengunaan APD dan APAR serta pelatihan K3 secara berkala. Memberikan tanda peringatan bahaya. Penyediaan APD pada seluruh subaktivitas untuk digunakan sesuai dengan kebutuhan saat melakukan aktivitas bekerja.
\end{abstract}

Kata kunci: Risiko, JSA, HIRARC, Mitigasi.

\section{Pendahuluan}

Perkembangan Ilmu pengetahuan dan teknologi telah membuat dunia industri meningkatkan efisiensi dan produktivitas melalui penggunaan alat-alat produksi yang sangat komplek. Peralatan kerja yang digunakan semakin komplek, maka kemungkinan terjadinya potensi bahaya kecelakaan kerja semakin tinggi. Hal ini juga mengharuskan penanganan dan pengendalian sebaik mungkin. Risiko adalah peluang terjadinya akan sesuatu yang memiliki dampak pada akibat yang diukur berkaitan dengan konsekuensi dan probabilitas. Risiko bahaya adalah seluruh kegiatan dalam tahapan proses yang berhubungan dengan faktor manusia, lingkungan dan mesin [1]. Setiap pekerjaan yang menggunakan area kerja, tenaga kerja serta alat kerja memiliki potensi bahaya dan risiko. Adanya kesalahan yang dilakukan oleh manusia (human error) maupun peralatan yang digunakan mempunyai Potensi bahaya dan risiko [2].

Job safety analysis (JSA) adalah metode yang bermanfaat dalam mengidentifikasi serta menganalisa bahaya dan risiko dalam suatu pekerjaan. Adanya identifikasi bahaya dalam setiap aktivitas proses produksi, dapat di identifikasi menyeluruh potensi bahaya kecelakaan kerja di lingkungan perusahaan tersebut. Untuk mengidentifikasi bahaya setiap aktivitas kerja dapat digunakan metode Job safety analysis (JSA), Teknik ini bermanfaat untuk mengidentifikasi dan menganalisa bahaya dalam suatu pekerjaan [3]. Analisis risiko dilakukan untuk memperkirakan risiko dengan mengalikan nilai faktor probabilitas (likelihood) dan konsekuensi (consequence) yang telah didapatkan dari proses identifikasi bahaya. HIRARC merupakan gabungan dari hazard identification, risk assessment dan risk control merupakan sebuah metode dalam mencegah atau meminimalisir kecelakaan kerja [4]. HIRARC (Hazard Identification Risk Assessment \& Risk Control) merupakan proses mengidentifikasi bahaya yang dapat terjadi dalam aktifitas Rutin ataupun Non Rutin dalam Perusahaan, untuk selanjutnya dilakukan penilaian risiko dari bahaya tersebut.

PT. Prima Alloy Steel Universal merupakan industri manufaktur bergerak dibidang pembuatan komponen otomotif yaitu velg kendaraan roda 4. Dalam proses produksi velg kendaraan roda 4 dibutuhkan proses casting untuk 


\section{KAIZEN : MANAGEMENT SYSTEMS \& INDUSTRIAL ENGINEERING JOURNAL VOL. 2 NO. 1 TEKNIK INDUSTRI UNIVERSITAS PGRI MADIUN}

membentuk pola atau model dari velg kendaraan roda 4. Dimana pada proses casting ini mempunyai risiko kerja yang sangat tinggi bagi karyawan. Menggunakan mesin casting dengan ukuran besar tentu saja mempunyai dampak risiko kerja yang harus dihindari melalui prosedur khusus yang digunakan saat melakukan pekerjaan tersebut. Tingkat keparahan atau severity dari risiko yang ada harus di identifikasi dengan jelas untuk mengindari risiko kerja.

Tujuan penelitian ini adalah melakukan identifikasi terhadap risiko bekerja di departemen casting dengan pendekatan Job Safety Analysis. sedangkan penilaian risiko serta penanggulangan risiko bahaya bekerja menggunakan metode HIRARC, hasil dari analisis tersebut digunakan untuk melakukan mitigasi terhadap setiap risiko yang terjadi di departemen casting.

\section{Metode Penelitian}

Penelitian ini menggunakan pendekatan Job Safety Analysis (JSA) dan metode Hazard Identification Risk Assessment and Risk Control (HIRARC) yaitu melakukan observasi terlebih dahulu pada departemen casting yang mempunyai risiko tertinggi dalam proses pembuatan Velg. Kemudian dilakukan analisis data dimulai dari mengidentifikasi bahaya bekerja pada aktivitas dan subaktivitas pada departemen casting juga kondisi produksi secara detail yang berpeluang atau berpotensi menyebabkan kecelakaan kerja yang kemudian dilakukan penilaian risiko dan menentukan tingkat risiko, yang selanjutnya akan dilanjutkan dengan analisis lebih lanjut dengan dikelompokkan berdasarkan sumber bahaya yang kemudian melihat penyimpangan apa yang terjadi, penyebab, akibat, selanjutnya dilakukan mitigasi risiko serta tindakan apa yang harus dilakukan terhadap sumber hazard tersebut.

\section{Hasil dan Pembahasan}

Dalam melakukan identifikasi bahaya dengan metode JSA, langkah-langkah yang diperhatikan, antara lain:

1. Aktifitas : isi dengan kegiatan yang di lakukan oleh pekerja di departemen casting PT. Prima Alloy Steel Universal.

2. Subaktifitas : isi dengan sub atau bagian dari aktifitas kegiatan pekerja di departemen casting PT. Prima Alloy Steel Universal.

3. Potensi Bahaya : isi dengan aspek bahaya aktual yang berhubungan dengan Keselamatan dan Kesehatan Kerja (K3).

4. Tindakan Pengendalian yang Telah Ada : menentukan apakah perusahaan memiliki pengendalian untuk mengelola aspek Keselamatan dan Kesehatan Kerja. Contoh : penggunaan masker untuk alat pelindung diri saat melakukan pekerjaan. Catatan: jika di perusahaan belum ada pengendalian bisa dikosongkan

Dari hasil wawancara kepada kepala bagian departemen casting maka dapat diperoleh 5 aktivitas yang dilakukan pada departemen casting yaitu proses charging dan peleburan bahan, proses penuangan bahan ke mesin cetak, proses mencetak bahan menjadi velg dimesin casting, proses pemotongan gelangan, proses loading dan pemberian stempel pada velg. Alur proses kerja depatemen casting ditunjukkan pada Gambar 1.

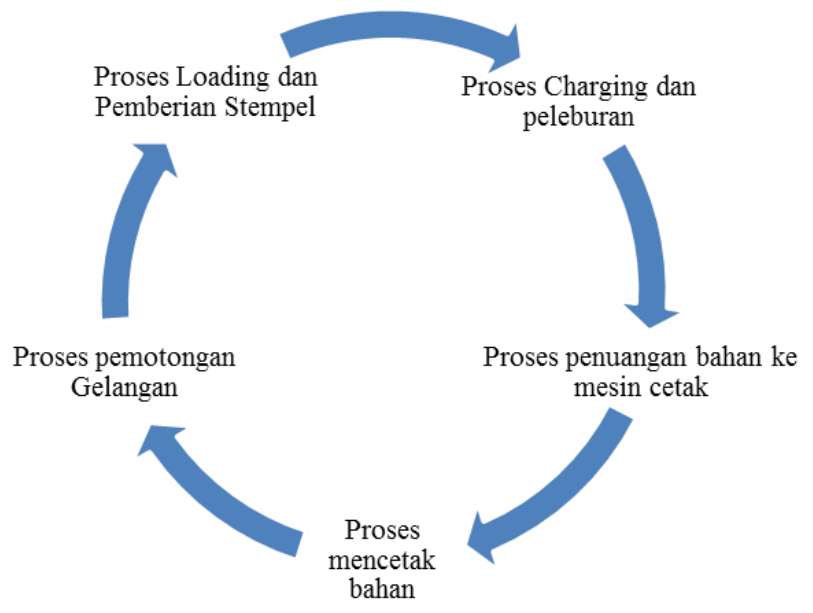

Gambar 1. Diagram proses kerja pada departemen casting

Copyright (C) 2019, Kaizen : Management Systems \& Industrial Engineering Journal ISSN 15222-96806 (print), ISSN $155222-95973$ (online) 


\section{KAIZEN : MANAGEMENT SYSTEMS \& INDUSTRIAL ENGINEERING JOURNAL VOL. 2 NO. 1 TEKNIK INDUSTRI UNIVERSITAS PGRI MADIUN}

Tabel 1. menunjukkan job safety analysis departemen casting. Dari hasil pengamatan yang dilakukan di departemen casting pencegahan atau tindakan pencegahan yang telah dilakukan oleh pihak perusahaan sangat kurang. Dari lima aktivitas proses produksi yang dilakukan dengan 13 subaktivitas. Dari tabel 1. diatas dapat diketahui bahwa tindakan pengendalian yang telah dilakukan oleh perusahaan sangat terbatas, tidak sesuai dengan standart keselamatan dan kesehatan kerja yang dapat menimbulkan terjadinya bahaya bagi pekerja di departemen casting.

Tabel 1. Jobs Safety Analysis Departemen Casting

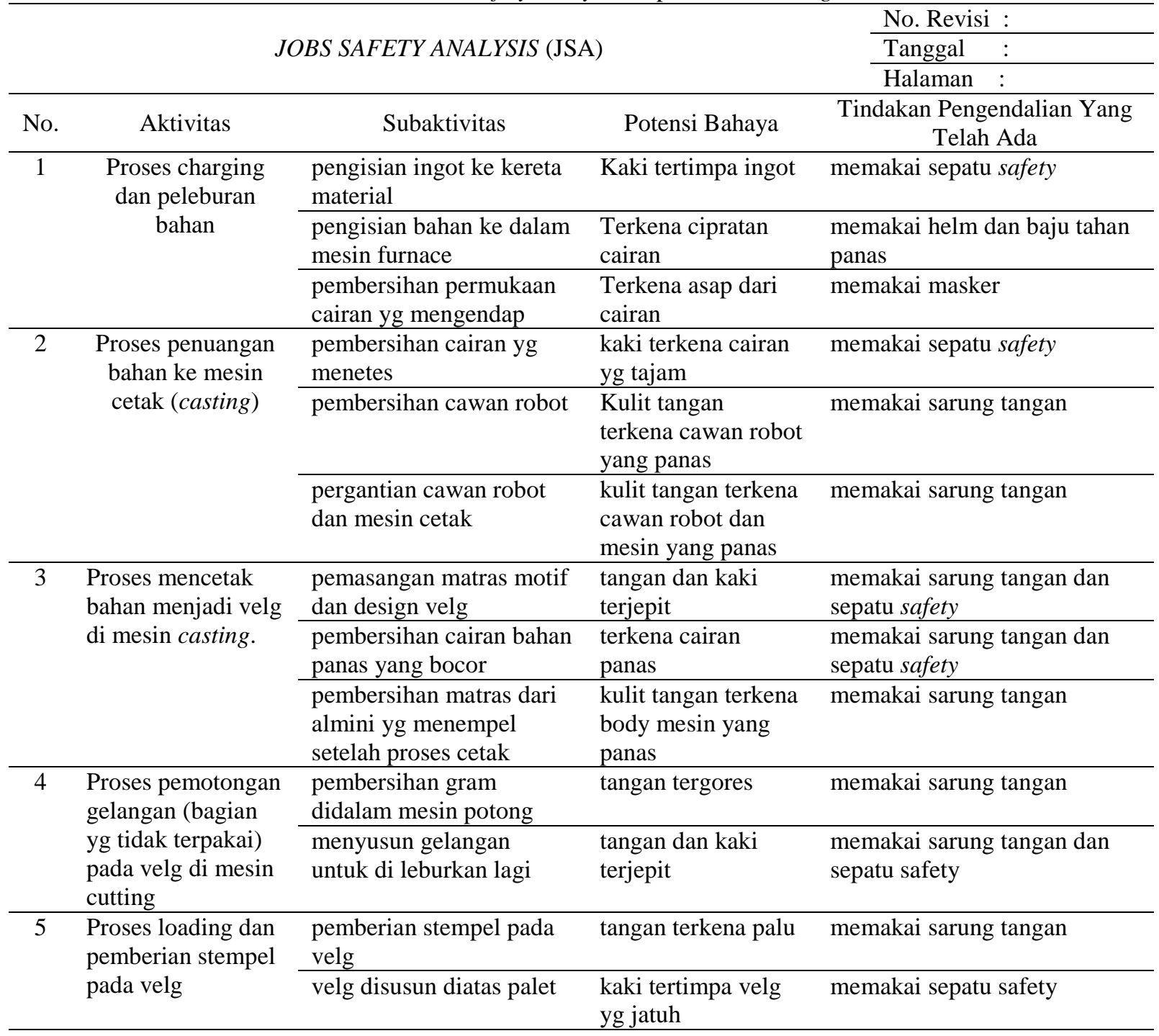

Selanjutnya untuk mengetahui tingkat terjadinya risiko setiap sub aktivitas di departemen casting maka dilakukan penilaian melalui penyebaran kuesioner kepada pihak terkait. Dimana hasil penilaian terhadap likelihood atau penilaian terhadap tingkat kemungkinan terjadinya kecelakaan kerja di departemen casting. Tabel 2. menunjukan nilai Likelihood masing-masing potensi bahaya yang ada pada 13 aktivitas kerja di departemen casting. Nilai tertinggi Likelihood terdapat pada aktivitas kerja pembersihan cairan panas dengan nilai likelihood sebesar 4 yang berarti suatu kejadian mungkin akan terjadi pada hampir semua kondisi bekerja pembersihan cairan panas.

Tabel 2. Tingkat Kemungkinan Terjadinya Kecelakaan Kerja di Departemen Casting

\begin{tabular}{cllc}
\hline No. & \multicolumn{1}{c}{ Aktivitas Kerja } & \multicolumn{1}{c}{ Potensi Bahaya } & Likelihood \\
\hline 1 & Pengisian ingot ke kereta material & Kaki tertimpa ingot & 3 \\
\hline 2 & Pengisian bahan ke dalam mesin furnace & Terkena cipratan cairan panas & 3 \\
\hline 3 & Pembersihan permukaan cairan yg mengendap & Terkena asap dari cairan & 2 \\
\hline
\end{tabular}

Copyright (C) 2019, Kaizen : Management Systems \& Industrial Engineering Journal ISSN 15222-96806 (print), ISSN 155222-95973 (online) 
KAIZEN : MANAGEMENT SYSTEMS \& INDUSTRIAL ENGINEERING JOURNAL VOL. 2 NO. 1 TEKNIK INDUSTRI UNIVERSITAS PGRI MADIUN

\begin{tabular}{cllc}
\hline No. & \multicolumn{1}{c}{ Aktivitas Kerja } & \multicolumn{1}{c}{ Potensi Bahaya } & Likelihood \\
\hline 4 & Pembersihan cairan yg menetes & Kaki terkena cairan yg tajam & 3 \\
\hline 5 & Pembersihan cawan robot & $\begin{array}{l}\text { Kulit tangan terkena cawan robot yang } \\
\text { panas }\end{array}$ & 2 \\
\hline 6 & Pergantian cawan robot dan mesin cetak & $\begin{array}{l}\text { Kulit tangan terkena cawan robot dan } \\
\text { mesin yang panas }\end{array}$ & 2 \\
\hline 7 & Pemasangan matras motif dan design velg & Tangan dan kaki terjepit & 3 \\
\hline 8 & Pembersihan cairan panas yang bocor & Terkena cairan panas & 4 \\
\hline 9 & Pembersihan matras dari almini yg menempel & Kulit tangan terkena body mesin yang & 2 \\
& setelah proses cetak & panas & 2 \\
\hline 10 & Pembersihan gram didalam mesin potong & Tangan tergores & 3 \\
\hline 11 & Menyusun gelangan untuk di leburkan lagi & Tangan dan kaki terjepit & 2 \\
\hline 12 & Pemberian stempel pada velg & Tangan terkena palu & 3 \\
\hline 13 & Velg disusun diatas palet & Kaki tertimpa velg yg jatuh & \\
\hline
\end{tabular}

Selanjutnya yaitu mengukur tingkat keparahan akibat terjadinya suatu risiko kerja yang terjadi. Pengukuran ini dilakukan untuk mengetahui seberapa besar tingkat konsekuensi atau keparahan yang dialami oleh para pekerja dan kerugian material yang harus ditanggung oleh pihak perusahaan. Tabel 3. maka dapat diketahui nilai consequence atau keparahan terhadap potensi bahaya bekerja di departemen casting untuk masing-masing aktvitas kerja. Nilai consequence tertinggi yaitu untuk aktivitas kerja pembersihan cairan panas yang bocor pada mesing casting dimana potensi bahaya yang dapat terjadi yaitu terkena cairan panas.

Tabel 3. Tingkat konsekuensi akibat terjadinya kecelakaan kerja di departemen casting

\begin{tabular}{|c|c|c|c|}
\hline No. & $\begin{array}{r}\text { Aktivitas Kerja } \\
\end{array}$ & $\begin{array}{r}\text { Potensi Bahaya } \\
\end{array}$ & Consequence \\
\hline 1 & Pengisian ingot ke kereta material & Kaki tertimpa ingot & 3 \\
\hline 2 & Pengisian bahan ke dalam mesin furnace & Terkena cipratan cairan panas & 4 \\
\hline 3 & Pembersihan permukaan cairan yg mengendap & Terkena asap dari cairan & 2 \\
\hline 4 & Pembersihan cairan yg menetes & Kaki terkena cairan yg tajam & 3 \\
\hline 5 & Pembersihan cawan robot & Kulit tangan terkena cawan robot yang panas & 2 \\
\hline 6 & Pergantian cawan robot dan mesin cetak & $\begin{array}{l}\text { Kulit tangan terkena cawan robot dan mesin yang } \\
\text { panas }\end{array}$ & 2 \\
\hline 7 & Pemasangan matras motif dan design velg & Tangan dan kaki terjepit & 3 \\
\hline 8 & Pembersihan cairan panas yang bocor & Terkena cairan panas & 4 \\
\hline 9 & $\begin{array}{l}\text { Pembersihan matras dari almini yg menempel } \\
\text { setelah proses cetak }\end{array}$ & Kulit tangan terkena body mesin yang panas & 3 \\
\hline 10 & Pembersihan gram didalam mesin potong & Tangan tergores & 2 \\
\hline 11 & Menyusun gelangan untuk di leburkan lagi & Tangan dan kaki terjepit & 3 \\
\hline 12 & Pemberian stempel pada velg & Tangan terkena palu & 3 \\
\hline 13 & Velg disusun diatas palet & Kaki tertimpa velg yg jatuh & 2 \\
\hline
\end{tabular}

Setelah diperoleh nilai likelihood dan consequence, maka selanjutnya dapat ditetapkan untuk risk rating masing-masing risiko bekerja. nilai risk rating diperoleh dari likelihood dikali dengan consequence. Berdasarkan tabel 4. maka diperoleh nilai risk rating yang merupakan hasil perhitungan dari nilai Likelihood dikalikan dengan dengan nilai Consequence. Diperoleh nilai risk rating tertinggi yaitu pada aktivitas pembersihan cairan panas yang bocor dengan nilai risk rating sebesar 16.

Tabel 4. Risk Rating Kecelakaan Kerja di Departemen Casting

\begin{tabular}{|c|c|c|c|c|c|}
\hline No. & Aktivitas Kerja & Potensi Bahaya & Likelihood & Consequence & $\begin{array}{c}\text { Risk } \\
\text { Rating }\end{array}$ \\
\hline 1 & Pengisian ingot ke kereta material & Kaki tertimpa ingot & 3 & 3 & 9 \\
\hline 2 & $\begin{array}{l}\text { Pengisian bahan ke dalam mesin } \\
\text { furnace }\end{array}$ & Terkena cipratan cairan panas & 3 & 4 & 12 \\
\hline 3 & $\begin{array}{l}\text { Pembersihan permukaan cairan yg } \\
\text { mengendap }\end{array}$ & Terkena asap dari cairan & 2 & 2 & 4 \\
\hline 4 & Pembersihan cairan yg menetes & Kaki terkena cairan yg tajam & 3 & 3 & 9 \\
\hline 5 & Pembersihan cawan robot & $\begin{array}{l}\text { Kulit tangan terkena cawan robot } \\
\text { yang panas }\end{array}$ & 2 & 2 & 4 \\
\hline 6 & Pergantian cawan robot dan mesin & Kulit tangan terkena cawan robot dan & 2 & 2 & 4 \\
\hline
\end{tabular}

Copyright (C 2019, Kaizen : Management Systems \& Industrial Engineering Journal ISSN 15222-96806 (print), ISSN 155222-95973 (online) 
KAIZEN : MANAGEMENT SYSTEMS \& INDUSTRIAL ENGINEERING JOURNAL VOL. 2 NO. 1 TEKNIK INDUSTRI UNIVERSITAS PGRI MADIUN

\begin{tabular}{|c|c|c|c|c|c|}
\hline No. & Aktivitas Kerja & Potensi Bahaya & Likelihood & Consequence & $\begin{array}{c}\text { Risk } \\
\text { Rating }\end{array}$ \\
\hline & cetak & mesin yang panas & & & \\
\hline 7 & $\begin{array}{l}\begin{array}{l}\text { Pemasangan matras motif dan } \\
\text { design velg }\end{array} \\
\end{array}$ & Tangan dan kaki terjepit & 3 & 3 & 9 \\
\hline 8 & $\begin{array}{l}\text { Pembersihan cairan panas yang } \\
\text { bocor }\end{array}$ & Terkena cairan panas & 4 & 4 & 16 \\
\hline 9 & $\begin{array}{l}\text { Pembersihan matras dari almini } \\
\text { yg menempel setelah proses cetak }\end{array}$ & $\begin{array}{l}\text { Kulit tangan terkena body mesin yang } \\
\text { panas }\end{array}$ & 2 & 3 & 6 \\
\hline 10 & $\begin{array}{l}\text { Pembersihan gram didalam mesin } \\
\text { potong }\end{array}$ & Tangan tergores & 2 & 2 & 4 \\
\hline 11 & $\begin{array}{l}\text { Menyusun gelangan untuk di } \\
\text { leburkan lagi }\end{array}$ & Tangan dan kaki terjepit & 3 & 3 & 9 \\
\hline 12 & Pemberian stempel pada velg & Tangan terkena palu & 2 & 3 & 6 \\
\hline 13 & Velg disusun diatas palet & Kaki tertimpa velg yg jatuh & 3 & 2 & 6 \\
\hline
\end{tabular}

Selanjutnya untuk mengetahui posisi masing-masing risk rating maka dilakukan pemetaan dengan menggunakan risk matrik, dimana Risk rating adalah nilai yang menunjukkan risiko yang ada berada pada tingkat rendah, menengah, tinggi, atau ekstrim. Hasil pemetaan risk rating masing-masing aktivitas kerja disajikan pada Tabel 5 Risk Matrik dibawah ini. Hasil pemetaan yang ditampilkan pada tabel 5 diatas maka dapat diketahui bahwa terdapat 2 aktivitas kerja dengan potensi bahaya masuk dalam kategori extreme risk yaitu aktivitas kerja pembersihan cairan panas yang bocor dan pengisian bahan ke dalam mesin furnace.

Tabel 5. Risk matrik

\begin{tabular}{|l|l|c|c|c|c|}
\hline \multirow{2}{*}{ Likelihood } & \multicolumn{5}{|c|}{ Consequence } \\
\cline { 2 - 6 } & $\begin{array}{c}1 \\
\text { (Insignificant) }\end{array}$ & $\begin{array}{c}2 \\
\text { (Minor) }\end{array}$ & $\begin{array}{c}3 \\
\text { (Moderate) }\end{array}$ & $\begin{array}{c}4 \\
\text { (Major) }\end{array}$ & $\begin{array}{c}5 \\
\text { (Catastrophic) }\end{array}$ \\
\hline 5 (Almost Certain) & & & & 8 & \\
\hline 4 (Likely) & & & & 2 & \\
\hline 3 (Moderate) & & 13 & $1,4,7,11$ & & \\
\hline 2 (Unlikely) & & $3,5,6,10$ & 9,12 & & \\
\hline 1 (Rare) & & & & & \\
\hline
\end{tabular}

4 aktivitas kerja masuk dalam kategori high risk yaitu Pengisian ingot ke kereta material, Pembersihan cairan yg menetes, Pemasangan matras motif dan design velg, Menyusun gelangan untuk di leburkan lagi. 3 aktivitas kerja masuk kategori moderate risk yaitu aktivitas Pembersihan matras dari almini yg menempel setelah proses cetak, Pemberian stempel pada velg, Velg disusun diatas palet. Sedangkan 4 aktivitas kerja masuk dalam kategori low risk yaitu aktivitas Pembersihan permukaan cairan yg mengendap, Pembersihan cawan robot, Pergantian cawan robot dan mesin cetak, Pembersihan gram didalam mesin potong. Prioritas pengendalian risiko dilakukan terhadap aktivitas yang masuk dalam kategori extreme risk yaitu aktivitas kerja pembersihan cairan panas yang bocor dan pengisian bahan ke dalam mesin furnace. Dengan beberapa langkah pengendalian bahaya bekerja atau mitigasi risiko melalui beberapa upaya pengendalian yang dapat dilakukan dengan mempertimbangkan kondisi area produksi, mesin dan peralatan yang digunakan. Tabel 6. Menunjukkan upaya pengendalian yang mungkin dilakukan.

Tabel 6. Upaya Pengendalian yang Direkomendasikan

\begin{tabular}{|c|c|c|c|c|}
\hline No. & $\begin{array}{c}\text { Aktivitas } \\
\text { Kerja }\end{array}$ & $\begin{array}{l}\text { Potensi } \\
\text { Bahaya }\end{array}$ & $\begin{array}{c}\text { Tindakan } \\
\text { Pengendalian Yang } \\
\text { Telah dilakukan } \\
\text { Perusahaan } \\
\end{array}$ & Upaya Pengendalian Yang Direkomendasikan \\
\hline 1 & $\begin{array}{l}\text { Pembersihan } \\
\text { cairan panas } \\
\text { yang bocor }\end{array}$ & $\begin{array}{l}\text { Terkena } \\
\text { cairan } \\
\text { panas }\end{array}$ & $\begin{array}{ll}\text { Memakai } & \text { sarung } \\
\text { tangan dan } & \text { sepatu } \\
\text { safety } & \end{array}$ & $\begin{array}{l}\text { a. Eliminasi : pengecekan posisi matras sebelum digunakan. } \\
\text { b. Subtitusi : menggunakan alat bantu saat membersihkan } \\
\text { cairan yang bocor. } \\
\text { c. Rekayasa engineering : mendesain alat bantu untuk proses } \\
\text { pembersihan cairan pada matras. } \\
\text { d. Pengendalian administratif: } \\
\text { 1) Membuat peraturan mengikat terkait penerapan } \\
\text { instruksi kerja. } \\
\text { 2) Memantau penggunaan APD pada pekerja. }\end{array}$ \\
\hline
\end{tabular}

Copyright (C 2019, Kaizen : Management Systems \& Industrial Engineering Journal ISSN 15222-96806 (print), ISSN 155222-95973 (online) 


\section{KAIZEN : MANAGEMENT SYSTEMS \& INDUSTRIAL ENGINEERING JOURNAL VOL. 2 NO. 1 TEKNIK INDUSTRI UNIVERSITAS PGRI MADIUN}

\begin{tabular}{|c|c|c|c|c|}
\hline No. & $\begin{array}{c}\text { Aktivitas } \\
\text { Kerja }\end{array}$ & $\begin{array}{l}\text { Potensi } \\
\text { Bahaya }\end{array}$ & $\begin{array}{c}\text { Tindakan } \\
\text { Pengendalian Yang } \\
\text { Telah dilakukan } \\
\text { Perusahaan }\end{array}$ & Upaya Pengendalian Yang Direkomendasikan \\
\hline & & & & $\begin{array}{l}\text { 3) Memberikan sanksi pada pekerja yang tidak } \\
\text { menggunakan APD secara lengkap } \\
\text { e. Penyediaan APD : Memfasilitasi pekerja dengan teropong } \\
\text { kepala, baju tahan api, sepatu dan sarung tangan. }\end{array}$ \\
\hline 2 & $\begin{array}{l}\text { Pengisian } \\
\text { bahan ke } \\
\text { dalam mesin } \\
\text { furnace }\end{array}$ & $\begin{array}{l}\text { Terkena } \\
\text { cipratan } \\
\text { cairan } \\
\text { panas }\end{array}$ & $\begin{array}{l}\text { Memakai helm dan } \\
\text { baju tahan panas }\end{array}$ & $\begin{array}{l}\text { a. Eliminasi : } \\
\text { 1) Menghilangkan bahan baku ingot yang tidak digunakan } \\
\text { dari sisi lubang pengisian bahan di mesin furnace. } \\
\text { 2) Mengganti bahan baku ingot yang kandungan } \\
\text { aluminiumnya lebih rendah namun kualitasnya tetap } \\
\text { baik dalam produksi dan tidak mengganggu kesehatan } \\
\text { pekerja. } \\
\text { b. Pengendalian Administratif : } \\
\text { 1) Membuat peraturan mengikat terkait penerapan } \\
\text { instruksi kerja. } \\
\text { 2) Memantau penggunaan APD pada pekerja. } \\
\text { 3) Memberikan sanksi pada pekerja yang tidak } \\
\text { menggunakan APD secara lengkap. } \\
\text { 4) Memberikan pelatihan kerja terkait K3 kepada pekerja } \\
\text { secara berkala. } \\
\text { 5) Melakukan pemeriksaan dan perawatan APAR secara } \\
\text { berkala. } \\
\text { c. Penyediaan APD : Memfasilitasi pekerja dengan sepatu, } \\
\text { sarung tangan tahan panas dan teropong muka }\end{array}$ \\
\hline
\end{tabular}

Berdasarkan hasil mitigasi risiko yang telah dijelaskan pada Tabel 6 diatas maka dapat dilakukan upaya perbaikan dari beberapa aspek terkait pengendalian risiko bekerja di departemen casting di PT. Prima Alloy Steel Universal sebagai berikut :

1) Eliminasi dilakukan dengan memperbaiki Standart Operation Procedure (SOP) pada setiap subaktivitas. Tindakan eliminasi tersebut yaitu pengecekan kualitas bahan baku ingot sebelum dimasukan kedalam mesin furnace, pembersihan bahan baku ingot untuk menghindari adanya pengendapan kotoran saat peleburan, pengecekan suhu cairan sebelum dituang ke matras, pembersihan sisa cairan material dilakukan setelah mesin dalam kondisi dingin.

2) Subtitusi direkomendasikan pada beberapa subaktivitas yaitu menggunakan alat bantu untuk membersihkan sisa material, menggunakan alat berat seperti forklif saat mengganti matras motif dan design velg. Penggunaan cairan pembersih untuk mempermudah proses pembersihan matras dari sisa pengecoran. Menggunakan pallet dengan ukuran yang lebih besar untuk menghindari jatuhnya gelangan yang tersusun diatas pallet.

3) Rekayasa engineering dibutuhkan untuk mempermudah subaktivitas agar dapat miminimalisir terjadinya kecelakaan kerja. Rekayasa engineering tersebut yaitu menerapkan ventilasi yang cukup untuk sirkulasi udara disekitar mesin furnace, mendesain alat bantu untuk proses pembersihan sisa material pada matras, mendesain pallet dengan ukuran lebih besar yang dilengkapi pembatas.

4) Pengendalian administratif dengan membuat peraturan yang mengikat terkait penerapan instruksi kerja, memantau pengunaan APD pada pekerja, memberikan tanda peringatan atau tanda keselamatan. Memberikan pelatihan kerja terkait K3 kepada pekerja secara berkala. Melakukan pemeriksaan dan perawatan APAR secara berkala.

5) Penyediaan APD pada seluruh subaktivitas untuk memfasilitasi pekerja sehingga dapat digunakan sesuai dengan kebutuhan saat melakukan aktivitas bekerja serta mamantau penggunaan APD sesuai fungsinya. 


\section{KAIZEN : MANAGEMENT SYSTEMS \& INDUSTRIAL ENGINEERING JOURNAL VOL. 2 NO. 1 TEKNIK INDUSTRI UNIVERSITAS PGRI MADIUN}

\section{Simpulan}

Berdasarkan hasil analisis dan pembahasan yang dilakukan maka dapat disimpulkan bahwa terdapat 5 aktivitas kerja dan 13 subaktivitas kerja di departemen casting dengan potensi bahaya yaitu kaki dan tangan terjepit, terkena cipratan cairan panas, kaki dan tangan terkena body mesin furnace yang panas serta tangan tergores saat pemotongan gelangan. Kaki tertimpa velg yang jatuh dari atas pallet. Hasil penilaian risiko diperoleh 2 aktivitas kerja dengan potensi bahaya masuk dalam kategori extreme risk yaitu aktivitas kerja pembersihan cairan panas yang bocor dan pengisian bahan ke dalam mesin furnace. 4 aktivitas kerja masuk dalam kategori high risk yaitu Pengisian ingot ke kereta material, Pembersihan cairan yg menetes, Pemasangan matras motif dan design velg, Menyusun gelangan untuk di leburkan lagi. 3 aktivitas kerja masuk kategori moderate risk yaitu aktivitas Pembersihan matras dari almini yg menempel setelah proses cetak, Pemberian stempel pada velg, Velg disusun diatas palet. Sedangkan 4 aktivitas kerja masuk dalam kategori low risk yaitu aktivitas Pembersihan permukaan cairan yg mengendap, Pembersihan cawan robot, Pergantian cawan robot dan mesin cetak, Pembersihan gram didalam mesin potong.

Tindakan penanggulangan terjadinya risiko dilakukan dengan beberapa aspek yaitu eliminasi dilakukan dengan memperbaiki Standart Operation Procedure (SOP) pada setiap sub aktivitas. Subtitusi direkomendasikan pada beberapa subaktivitas yaitu menggunakan alat bantu untuk membersihkan sisa material, menggunakan alat berat seperti forklif saat mengganti matras motif dan design velg. Rekayasa engineering dibutuhkan untuk mempermudah subaktivitas agar dapat miminimalisir terjadinya kecelakaan kerja. Pengendalian administratif dengan membuat peraturan yang mengikat terkait penerapan instruksi kerja, memantau pengunaan APD dan APAR serta pelatihan K3 secara berkala. Memberikan tanda peringatan atau tanda keselamatan. Penyediaan APD pada seluruh subaktivitas untuk memfasilitasi pekerja sehingga dapat digunakan sesuai dengan kebutuhan saat melakukan aktivitas bekerja serta mamantau penggunaan APD sesuai fungsinya.

\section{Daftar Pustaka}

[1] F. Mallapiang and I. A. Samosir, "Analisis Potensi Bahaya Dan Pengendaliannya Dengan Metode HIRAC," Al-Sihah Public Heal. Sci. J., vol. VI, no. 2, pp. 350-362, 2014.

[2] A. Despriadi, "Bongkar Muat Di Pelabuhan PT Sarana Citranusa Kabil dengan Metode HIRARC," J. Tek. Ibnu Sina, vol. 2, no. 1, pp. 119-125, 2017.

[3] P. Martino, D. I. Rinawati, and R. Rumita, "Analisis Identifikasi Bahaya Kecelakaan Kerja Menggunakan Job Safety Analysis (JSA) Dengan Pendekatan Hazard Identification, Risk Assessment And Risk Control ( HIRARC )," Ind. Eng. Online J., vol. 4, no. 2, 2015.

[4] I. Nurmawanti, S. Widaningrum, and M. Iqbal, "Identifikasi Keselamatan dan Kesehatan Kerja (K3) dengan Menggunakan Metode HIRARC untuk Memenuhi Requirement OHSAS 18001 : 2007 Terkait Klausul 4.4.6 di PT. Beton Elemenindo Perkasa," e-Proceeding Eng., vol. 2, no. 2, pp. 4568-4575, 2015. 